\title{
Effect of Vitamin C Supplementation on Colonic Anastomotic Healing in the Presence of Peritonitis- An Experimental Study in Rats
}

\author{
Pradeep Kumar Kothiya ${ }^{1}$, Deepti B. Sharma², Fanindra S. Solanki³, Anil K. Tiwari ${ }^{4}$, S. K. Chandrakar ${ }^{5}$ \\ ${ }^{1}$ Department of Surgery, NSCB MC, Jabalpur, Madhya Pradesh, India. ${ }^{2}$ Department of Surgery, NSCB MC, Jabalpur, \\ Madhya Pradesh, India. ${ }^{3}$ Department of Surgery, NSCB MC, Jabalpur, Madhya Pradesh, India. ${ }^{4}$ Department of Surgery, \\ NSCB MC, Jabalpur, Madhya Pradesh, India. ${ }^{5}$ Department of Pathology, NSCB MC, Jabalpur, Madhya Pradesh, India.
}

\section{ABSTRACT}

\section{BACKGROUND}

ascorbic acid plays a critical role in wound repair and healing/regeneration process as it stimulates collagen synthesis. Its effect on jejunal and colonic anastomosis is already established. We assessed its role on colonic anastomosis healing in presence of peritonitis and without peritonitis. Assessment was done by recording bursting pressure of anastomosis and histological features of healing.

\section{METHODS}

This experimental study was conducted in 48 Albino Rats (mean weight of $180 \mathrm{~g}$ ). All rats were subjected to exploratory laparotomy with colonic resection anastomosis and were divided into six groups. Group A and B control, Group C and D were supplemented with Vitamin C in low dose i.e. $100 \mathrm{mg} / \mathrm{Kg}$ body, Group E and F high dose of Vitamin C i.e. $200 \mathrm{mg} / \mathrm{Kg}$ body wt. Vitamin C was given for seven days intra muscularly. Peritonitis was created by cecal ligation and puncture (CLP) in half the number of rats $(n=24)$, in each group. Every rat was re-explored on $7^{\text {th }}$ postoperative day and anastomotic segments were harvested for bursting pressure measurement and then sent for histopathology examination.

\section{RESULTS}

Bursting Pressure of group D $(100 \mathrm{mg})$ was significantly raised $(\mathrm{p}<0.05)$ as compared to group B in the presence of peritonitis. Group F (200 gm vit C) showed significantly higher bursting pressure than group $D(p<0.05)$. The findings of analysis of variance (ANOVA) showed that the mean BP of all the groups differs significantly from each other $(\mathrm{p}<0.05)$. High dose vitamin $\mathrm{C}$ supplementation gave more strength to anastomosis than low dose even in presence of peritonitis. The average histopathological examination score was 5.24 (Group E) $(\mathrm{p}<0.05)$. i.e., best healing among all groups. It had better effect even in presence of peritonitis - 4.62 in Group F. Healing score in this group was greater than group A, B, C, D and less than in group E.

\section{CONCLUSIONS}

Presence of fecal peritonitis hampers the process of healing of colonic anastomosis by impairing reparative collagen synthesis, its deposition and anastomotic strength reflected by decreased bursting pressure and decrease HPE score. Supplementation of systemic ascorbic acid increases intestinal anastomotic healing by increasing collagen accumulation reflected by increased bursting pressure and increase HPE score even in presence of peritonitis. High dose ascorbic acid supplementation had better effect on intestinal anastomotic healing. Importance of ascorbic acid in colonic anastomosis healing is yet to be evaluated in human beings.

\section{KEY WORDS}

Vitamin C, Ascorbic Acid, Intestinal Anastomoses, Colonic Anastomoses, Anastomotic Healing, Healing in the Presence of Peritonitis
Corresponding Author: Dr. Pradeep Kumar Kothiya, C/o. RKJain, Near Bhagwati School, Ganganagar Garma, Jabalpur, Madhya Pradesh, India.

E-mail: pradeepkothiya48@gmail.com

\section{DOI: $10.14260 /$ jemds $/ 2020 / 380$}

Financial or Other Competing Interests: None.

How to Cite This Article:

Kothiya PK, Sharma DB, Solanki FS, et al. Effect of vitamin $C$ supplementation on colonic anastomotic healing in the presence of peritonitis- an experimental study in rats. J. Evolution Med. Dent. Sci. 2020;9(23):1730-1733, $10.14260 /$ jemds $/ 2020 / 380$

DOI:

Submission 23-12-2019,

Peer Review 12-05-2020,

Acceptance 19-05-2020,

Published 08-06-2020.

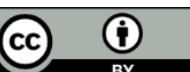




\section{BACKGROUND}

Colonic resection and subsequent anastomosis are widely performed operations in the field of surgery for colonic malignancies, devascularised injury and infective pathology. Although these operations are generally safe, leakage of the anastomosis is a serious complication and may even result in death. Several factors, such as bowel preparation prior to surgery, surgical technique, nutritional status, and intervening pathological conditions, have been identified as significantly influencing the healing of colonic anastomoses. Despite the use of optimal surgical techniques and medical treatments, the integrity of intestinal anastomosis may be compromised, resulting in wound dehiscence. The frequency of this complication, which carries a high morbidity and mortality rate, increases if surgery has to be performed in the presence of high-risk situations, such as surgeries performed in emergency settings, on infected and necrotic stumps, in unsafe anatomical areas (rectum, oesophagus), or in patients with metabolic derangements. Faecal contamination and peritonitis have significant influence on healing of colonic anastomosis by interfering with collagen synthesis and healing process. In large number of instances, resection anastomosis has to be done in presence of peritonitis. Presence of peritonitis hampers the process of healing of anastomosis by impairing reparative collagen synthesis and altering collagen types I and III gene expression. It resulted in decreased anastomotic bursting pressure due to decrease mechanical strength. ${ }^{(1)}$

Managing an anastomotic leak typically necessitates a prolonged hospitalization, greatly increases cost and often requires one or more re-operations to control sepsis ascorbic acid plays a critical role in wound repair and healing/regeneration process as it stimulates collagen synthesis. Adequate supplies of ascorbic acid are necessary for normal healing process especially for post-operative patients. It has been suggested that there will be rapid utilization of ascorbic acid for the synthesis of collagen at the site of wound during post-operative period. Its effect on jejunal and colonic anastomosis is already established.(2,3)

Vitamin $\mathrm{C}$ is an important dietary anti -oxidant, it significantly decreases the adverse effect of reactive species such as reactive oxygen and nitrogen species that can cause oxidative damage to macromolecules such as lipids, DNA and proteins. (4) This additive effect decreases the adverse effect of peritonitis. Vitamin C decreases the adverse effect of peritonitis to large extend by increasing wound healing via increased hydroxyproline content and tensile strength. Supplementation of ascorbic acid has been shown to support myoelectrical activity of the gut by exerting a neurotrophic effect on VIP-ergic neurons of the ileum. In addition to the scavenging effect, ascorbic acid is mandatory in the hydroxylation of lysine and proline in collagen synthesis and cross linkage. It is widely accepted that increased collagen production in the tissue contributes to the final strength of the wound

The effect of vitamin $\mathrm{C}$ on wound healing is known but none of these studies addressed the question of wound healing clinically or experimentally in presence of peritonitis.

This fact motivates us to evaluate the effect Vitamin $C$ on anastomotic healing of colon. This assessment was done in presence of peritonitis. Vitamin C was used in low dose and high dose. Healing was also evaluate by measuring bursting pressure and histological assessment of anastomosis.

\section{METHODS}

This experimental study was conducted in experimental lab of department of surgery of our institute. We had taken permission from Animal Ethics committee of our institute. It was composed of 48 Albino Rats with mean weight of $180 \mathrm{~g}$. The rats were kept at room temperature and provided with free access to standard (Bengal gram) high protein and tap water prior to the experiment.

After preliminary preparation rats were anesthetized by inhalation anaesthesia. Ether was used as the anaesthetic agent by the ether jar technique as it can be easily administered, has rapid induction. Abdomen was opened and Colonic resection and anastomosis was performed with interrupted 6-0 absorbable polyglactin 910 violet (Vicryl Ethicon) sutures in all rats, $4 \mathrm{~cm}$ distal to ileocecal region. All rats were divided into six groups. Group A and B control, Group C and D were supplemented by daily intra-muscular injections with Vitamin C in low dose i.e. $100 \mathrm{mg} / \mathrm{Kg}$ body, Group E and F were supplemented with high dose of Vitamin C i.e. $200 \mathrm{mg} / \mathrm{Kg}$ body wt. Vitamin C was given for seven days. First dose was given immediate post operatively. Cecal ligation and puncture (CLP) was done in half number of rats $(n=24)$, in each group, according to method describe by Daniel Rittirs(5) to create moderate peritonitis.

\section{Rats were divided into total six groups}

- Group A - RA without peritonitis.

- $\quad$ Group B - RA + fecal peritonitis.

- Group C - RA + 100 mg ascorbic acid.

- Group D - RA + 100 mg ascorbic acid + fecal peritonitis.

- Group E - RA +200 mg ascorbic acid.

- Group F - RA + 200 mg ascorbic acid + fecal peritonitis.

Every rat was re-explored on $7^{\text {th }}$ post-operative day. Macroscopic examination of abdominal cavity was done for adhesions, leaks and abscess formation. A colonic segment of $4 \mathrm{~cm}$ of anastomotic site was harvested and subjected to assessment of bursting pressure and then histological assessment of specimen.

\section{Measurement of Bursting Pressure}

We assessed the bursting pressure with the help of sphygmomanometer. A ten $\mathrm{cm}(10 \mathrm{~cm})$, number $8 \mathrm{f}$ infant feeding tube was fixed to cuff of sphygmomanometer cuff and made it air tight. Other end of tube was fixed with one end of harvested intestinal segment with other end clamped with artery forceps. Sphygmomanometer cuff was inflated. The pressure of cuff was transmitted to segment of gut, which was dipped into water. The pressure at which air bubbles come out of anastomotic site signifies bursting of suture line. This pressure signifies bursting pressure of segment of that gut. After assessing the bursting pressure colonic segment was histologically examine for Neutrophilic infiltration, 
Lymphocytic infiltration, Collagen deposition, Granuloma formation, Mucosal continuity.(3)

\section{Histopathological Assessment of Anastomotic Site}

The specimen were fixed in $10 \%$ formaldehyde solution and embedded in paraffin. Sections that contain peri-anastomotic tissue (4-5 micro meter in thickness) were cut and mounted on glass slides. The staining was performed using the haematoxylin - eosin method. The sections were evaluated by a semi- quantitative method to assess mucosal healing. The inflammatory reaction was quantified, and graded by scoring polymorphonuclear leucocytes, macrophages, fibroblast composition, and neovascularization in the sections. Table - 1

\begin{tabular}{|ccccc|}
\hline Score & $\begin{array}{c}\text { Mucosal } \\
\text { Healing }\end{array}$ & $\begin{array}{c}\text { Inflammation } \\
\text { (Neutrophil } \\
\text { Infiltration), \% }\end{array}$ & $\begin{array}{c}\text { Macrophage } \\
\text { Fibroblast } \\
\text { Infiltration }\end{array}$ & $\begin{array}{c}\text { Neovascula- } \\
\text { rization }\end{array}$ \\
0 & No healing & - & None & None \\
1 & Epithelium & $<25$ & Moderate & Moderate \\
2 & Submucosa & $25-50$ & Severe & Severe \\
3 & Muscularis mucosa & $50-75$ & & \\
4 & Complete healing & 75 & \\
\hline \multicolumn{5}{|c}{ Table 1. Histological Scoring of Healing } \\
\hline
\end{tabular}

\section{Statistical Analysis}

Statistical analysis was done by Post Hoc test with ANOVA.

\section{RESULTS}

Every rat was explored on $7^{\text {th }}$ post- operative day. Macroscopic examination was done and $4 \mathrm{~cm}$ colonic segment of anastomotic site was harvested. Bursting pressure was measured in colonic segment of each rat of every group and average bursting pressure was calculated of each group. (Table-2)

\begin{tabular}{|c|c|c|}
\hline Group & Name of Group & Average BP (mmHg) \\
\hline A & RA without peritonitis & $133.25 \pm 15.78$ \\
\hline B & $\mathrm{RA}+$ faecal peritonitis & $111.00 \pm 14.54(p=>0.05)$ \\
\hline $\mathrm{C}$ & $\mathrm{RA}+100 \mathrm{mg}$ ascorbic acid & $174.25 \pm 19.67$ \\
\hline D & $\mathrm{RA}+100 \mathrm{mg}$ ascorbic acid + faecal peritonitis & $135.00 \pm 16.59$ \\
\hline $\mathrm{E}$ & RA+200 mg ascorbic acid & $201.00 \pm 17.07(p=<0.05)$ \\
\hline $\mathrm{F}$ & $\mathrm{RA}+200 \mathrm{mg}$ ascorbic acid + faecal peritonitis & $173.75 \pm 35.09$ \\
\hline \multicolumn{3}{|c|}{ Table 2. Average Bursting Pressure in Each Group } \\
\hline
\end{tabular}

Fecal peritonitis had deleterious effect on colonic healing after resection anastomosis as average bursting pressure in groups with peritonitis i.e. B, D, F (139.91 $\mathrm{mmHg}$ ) were significantly lower as compared to group without peritonitis i.e. A, C, E. (169.5 mmHg) Vitamin C had added advantage on colonic healing. Bursting pressure in group who had vitamin - C (100 mg supplementation) was significantly improved as compared to sham operated group i.e. group A. Vitamin C was given in higher dose i.e. $200 \mathrm{mg}$, showed significant better results.

Bursting Pressure of group D (100 mg) was significantly raised $(\mathrm{p}<0.05)$ as compared to group $B$ in presence of peritonitis. Group F (200 gm vit C) showed significantly higher bursting pressure than group $D(p<0.05)$. The finding of analysis of variance (ANOVA) showed that the mean BP of all the groups differ significantly to each other $(p<0.05)$. These findings are suggestive of beneficial effect of vitamin $C$ on colonic anastomotic healing in presence of peritonitis. High dose vitamin C supplementation gave more strength to anastomosis than low dose even in presence of peritonitis. (Table -2).

\begin{tabular}{|c|c|c|}
\hline Group & Name of Group & $\begin{array}{c}\text { Average Histological } \\
\text { Score }\end{array}$ \\
\hline A & RA without peritonitis & $3.37(3.37+1.06)$ \\
\hline B & $\mathrm{RA}+$ faecal peritonitis & $2.25(2.25+.89)$. \\
\hline $\mathrm{C}$ & $\mathrm{RA}+100 \mathrm{mg}$ ascorbic acid & $3.87(3.87+1.31)$ \\
\hline D & $\mathrm{RA}+100 \mathrm{mg}$ ascorbic acid + faecal peritonitis & $3.37(3.37+1.49)$ \\
\hline E & $\mathrm{RA}+200 \mathrm{mg}$ ascorbic acid & $5.24(5.24+1.67)$ \\
\hline $\mathrm{F}$ & $\mathrm{RA}+200 \mathrm{mg}$ ascorbic acid + faecal peritonitis & $4.62(4.62+1.51)$ \\
\hline \multicolumn{3}{|c|}{ Table 3. Histological Score } \\
\hline
\end{tabular}

Histological score of this group A was 3.37 and that of group B examination score was 2.25 , suggestive of poor healing of anastomotic site in presence of peritonitis. $(\mathrm{p}<0.05)$ The average histopathological score of Group C was greater than group A (3.87>3.37), suggesting that low dose vitamin $\mathrm{C}$ did not have significant effect on colonic anastomosis healing but better and significant effect on colonic healing in presence of peritonitis. (Group D $>$ Group B $-3.37>2.25$ )

High dose Vitamin C (200 mg) had good effect on anastomotic healing in absence of peritonitis. The average histopathological examination score was 5.24 (Group E) $(p<0.05)$. i.e., best healing among all groups. It had better effect even in presence of peritonitis - 4.62 in Group F. Healing score in this group was greater than group A, B, C, D and less than group E. (Table 3).

\section{DISCUSSION}

Peritonitis is a known cause of anastomotic dehiscence in the colon, yet the mechanism by which this occurs is not fully understood. Peritonitis induced by cecal ligation and puncture, alters collagen types I and III gene expression and impairs reparative collagen synthesis in the healing colon. Studies of animal models of sepsis have discovered that parenteral ascorbate improves survival, the intestinal anastomosis healing and have beneficial effects on cellular functions of both the innate and adaptive immune system. $(6,7,8)$ Ahrendt $\mathrm{GM}^{(1)}$ et al also concluded that sepsis impairs healing in all colon segments that were analyzed in the animals that underwent cecal ligation and puncture compared with control animals which was reflected by decrease in bursting pressure. In this study it is evident as average bursting pressure in groups with peritonitis i.e. B, D, F (139.91 mmHg) were significantly lower as compared to group without peritonitis i.e. A, C, E. $(169.5 \mathrm{mmHg}) .(\mathrm{p}<.005)$.

Frank J et al(9) also studied the Influence of sepsis on colonic bursting pressure and collagen concentration and found that colon anastomotic bursting pressure was decreased in the septic rats compared to the sham group $152.0+7.0 \mathrm{mmHg}$ vs. $125.0+5.0 \mathrm{mmHg},(\mathrm{p}<0.003)$ results are similar to our study.

The histopathological scores of M. H. Cevikel(1) et al. Study indicates improved healing in groups $3(200 \mathrm{mg} / \mathrm{Kg})$ $(6.0 \pm 0.2)$ and group $2(100 \mathrm{mg} / \mathrm{Kg})(4.4 \pm 0.4)$, compared to sham treatment group $1(2.7 \pm 0.3 ; \mathrm{p}<0.05)$. Intestinal healing was significantly improved in the rats that were treated with 
high dose $(200 \mathrm{mg} / \mathrm{Kg})$ and low dose $(100 \mathrm{mg} / \mathrm{Kg})$ ascorbic acid in our study as the histopathological scores indicated significantly improved healing in group E $(5.2500+1.66905)$ compared to group A $(3.6250+1.06066)(\mathrm{p}<0.05)$.

\section{CONCLUSIONS}

Presence of fecal peritonitis hampers the process of healing of colonic anastomosis by impairing reparative collagen synthesis, its deposition and anastomotic strength reflected by decreased bursting pressure and decreased HPE score. Supplementation of systemic ascorbic acid increases intestinal anastomotic healing by increasing collagen accumulation, inflammatory response and anastomotic strength reflected by increased bursting pressure and increased HPE score even in presence of peritonitis. High dose ascorbic acid supplementation had better effect on intestinal anastomotic healing. Importance of ascorbic acid in colonic anastomosis healing is yet to be evaluated in human beings.

\section{REFERENCES}

[1] Ahrendt GM, Tantry US, Barbul A. Intra-abdominal sepsis impairs colonic reparative collagen synthesis. Am J Surg 1996;171(1):102-8.
[2] Petroianu A, Alberti LR. Effect of oral supplementation of vitamin $\mathrm{C}$ on intestinal anastomotic resistance. Rev Col Bras Cir 2011;38(1):54-8.

[3] Cevikel MH, Tuncyurek P, Ceylan F, et al. Supplementation with high-dose ascorbic acid improves intestinal anastomotic healing. Eur Surg Res 2008;40(1):29-33.

[4] Naidu AK. Vitamin C in human health and disease is still a mystery? An overview. Nutrition Journal 2003;2:7.

[5] Rittirsch D, Huber-Lang MS, Flierl MA, et al. Immunodesign of experimental sepsis by Cecal ligation and puncture. Nat Protoc 2009;4(1):31-6.

[6] Wilson JX. Evaluation of vitamin C for adjuvant sepsis therapy. Antioxid Redox Signal 2013;19(17):2129-40.

[7] Danielski LG, Walczewski E, de Jesus CR, et al. Preoperative vitamin C supplementation improves colorectal anastomotic healing and biochemical parameters in malnourished rats. Int J Colorectal Dis 2016;31(11):1759-66.

[8] Carr AC, Maggini S. Vitamin C and immune function. Nutrients 2017;9(11):1211.

[9] Thornton FJ, Ahrendt GM, Schaffer MR, et al. Sepsis impairs anastomotic collagen gene expression and synthesis: a possible role for nitric oxide. Journal of Surgical Research 1997;69(1):81-6. 